\title{
IDENTIDADE NEGRA, EDUCAÇÃO E SILENCIAMENTO: O OLHAR PEDAGÓGICO PARAA APLICAÇÃO DA LEI 10.639/03
}

Quecia Silva Damascena ${ }^{1}$

Eduardo Oliveira Miranda ${ }^{2}$

Maria Cecília de Paula Silva ${ }^{3}$

\section{CAMINHOS INICIAIS}

A educação é um processo inerente a humanidade, onde seu exercício se realiza em diferentes espaço, porém ao direcionarmos o olhar para o espaço escolar nos deparamos com intenções que perpassam pela escolarização e exercício de cidadania. Sendo os sujeitos desses espaços cidadãos diversos, tratar das diferenças enquanto diversidade e característica da humanidade configura-se como estratégia para compreendermos como a educação pode contribuir para uma sociedade mais justa, igualitária e democrática.

Contudo, o trato da diversidade no cotidiano escolar tem apresentado irrisória relevância no que orienta a Lei 10.639/03 consideramos que esse déficit é uma constante no contexto escolar, bem como, na formação dos professores. Tal silenciamento se traduz com a ausência de projetos para construção de identidade negra positiva dos educandos, abordar o silenciamento nos conduz ao campo da naturalização, onde se normaliza o desprestigio da temática étnico racial na formação da identidade docente. Em seu texto "É preciso africanizar a universidade" a pesquisadora Narcimária Luz (2013) evidencia as estratégias ideológicas orquestradas para realçar a intelligentsia ocidental e ao mesmo tempo reafirmar que a "universidade não acredita e não consegue conceber que há uma epistemologia africano-brasileira legítima pulsando suas territorialidades negras, [...], e que contemporaneamente entra na universidade através de gerações de afrodescendentes" (LUZ, 2013, p. 176).

\footnotetext{
${ }^{1}$ Pedagoga pela Faculdade de Educação da Universidade Federal da Bahia - FACED/UFBA. Mestranda no Programa de Pós-Graduação em Educação da FACED/UFBA. Pós-graduanda em Educação em Direitos Humanos - UFBA. queciadamascena@yahoo.com.br.

${ }^{2}$ Licenciado em Geografia e Mestre em Desenho, Cultura e Interatividade pela Universidade Estadual de Feira de Santana - UEFS. Pedagogo - FAC. Doutorando no Programa de Pós-Graduação em Educação da FACED/UFBA. eduardomiranda48@gmail.com.

${ }^{3}$ Pós-doutorado em sociologia/educação pela Université de Strasbourg. Professora Associada e pesquisadora do Programa de Pós-Graduação e graduação - FACED/UFBA. Coordena o grupo de pesquisa HCEL - História da Cultura Corporal, Educação, Esporte, Lazer e Sociedade. Doutora e Mestre pela Universidade Gama Filho/ RJ. cecilipaula@gmail.com.
} 
Assim, (MUNANGA, 2004, p 15) "a superação do racismo ainda presente em nossa sociedade é um grande imperativo", sendo de grande relevância incluir nos planos de cursos conteúdos históricos e sociais que apresentem aos educandos o conhecimento da sua história de forma positiva, e não estereotipada, inferiorizada como tem sido trabalhado historicamente em nosso currículo escolar. Entendemos que acessar as africanidades brasileiras permite o trabalho com bases de informações históricas, pois como afirma Petronilha Silva (2005, p.155) precisamos reivindicar que em nossos currículos escolares sejam abordados conteúdos que "valorizem igualmente as diferentes e diversificadas raízes das identidades dos distintos grupos que constituem o povo brasileiro". Afinal a educação é um dos terrenos de possibilidades nesse esforço de contribuir para a construção coletiva de uma consciência intercultural.

Destarte, a escola precisa promover vivencias culturais as quais não desperdicem as experiências das variadas etnias (BOAVENTURA, 2002), o que possibilita aos sujeitos envoltos no chão da escola a ter contato com particularidades negligenciadas, tais como: identidade negra, colonização das práticas pedagógicas e dos livros didáticos, entre outras questões pontuais para a formação da personalidade dos educandos negro e não negros.

A construção negativa pode afetar não somente os alunos em sua autoestima, mas também em sua aprendizagem, reflexão que precisa ser fomentada dentro da escola e nos espaços de formação docente. Infelizmente a negação do racismo é um discurso pronto para alguns educadores que na verdade reproduzem o discurso de democracia racial existente em nossa sociedade, porém a discriminação racial esta naturalizada no cotidiano escolar, o que nos inquieta. Onde se o educador não reformular suas ações pedagógicas como romperá com a estrutura de valores históricos em que o negro é considerado somente para as condições de subalternidade, inferioridade fisiológica, marginalização cultural e religiosa? Para isso potencializar o trato com as africanidades brasileiras poderá promover aprendizagens que valorizem as identidades étnico-histórico-cultural.

É de extrema importância discutir dentro do espaço escolar junto aos alunos e sujeitos do espaço, bem como nos espaços acadêmicos e de formação dos educadores, considerando que as construções sociais se traduzem como motivador dos conflitos entre as relações raciais, pois o mito de democracia racial em nossa sociedade reflete na educação como silenciador, ou seja, o combate à discriminação racial precisa ser uma inquietação recorrente na pratica dos educadores. É importante ressaltar como destaca Nilma Lino Gomes (2005, p. 41) que:

A identidade não é algo inato. Ela se refere a um modo de ser no mundo e com os outros. É um fator importante na criação das redes de relações e de referências culturais dos grupos sociais. Indica traços culturais que se expressam através de 
práticas linguísticas, festivas, rituais, comportamentos alimentares e tradições populares referências civilizatórias que marcam a condição humana.

Portanto, um problema social se estabelece quando omitimos a presença do racismo, as práticas discriminatórias já estão internalizadas em todos os espaços de convivência como questões de ordem natural e essa naturalização prejudica a mobilidade social do negro, pois quando avaliamos o cotidiano escolar as evidencias desse problema social se evidencia nos indicadores de aprendizagem, no rendimento escolar e na evasão dos espaços. Existe uma grande necessidade de se abordar um currículo intercultural, diverso e plural para que assim possamos desconstruir as ideologias do colonizador, pois a consciência ideológica funciona como reflexo, como o processo observatório, são as representações que estão postas que promovem as construções de personalidade. Segundo Jeruse Romão (2002, p. 164):

O sentimento de inferioridade imediatamente sugere um sentimento de limite, o de poder apenas uma parte e não o todo. A impossibilidade de ser completo motiva o desprezo das necessidades de enfrentar desafios tão necessários para aprender sobre si, o outro e o mundo.

Para que o aluno possa desenvolver um sentimento de pertencimento, de igualdade e representatividade em sua sociedade, ele buscará como norteador seu referencial histórico, que por sua vez precisa ser trabalhado no campo da diversidade, pois é através da consciência da existência multicultural que o educando construirá também o respeito à constituição subjetiva do outro, desconstruindo os estigmas do racismo presente em nossa educação.

Quando falamos dos conteúdos históricos que são apresentados em sala, encontramos as marcas do escravismo e do colonialismo português, neles o negro considerado como mercadoria, a marginalização de sua cultura e de sua religião é caracteristicamente política e ideológica, o que consequentemente não permite a criança negra em especial se sentir representada e ainda que compreenda sua relação racial, o processo de identificação e afirmação será comprometido. Nesse viés, o estigma racial alveja aos afrodescendentes questões psicológicas desprestigiadoras da autoestima, como elucida Bartolomeu Mendes (1998):

Um indivíduo, ou uma coletividade que se encontre em condições estigmatizadas, pode até se alinhar a uma tendência de desânimo ou depreciação que chegue a afetar a sua auto-estima empurrando-o para baixo. Seus sentimentos sobre o que realmente é se enfraquecem de tal forma que pode leva-lo a acreditar na sua suposta "incapacidade" (p.43). 
Portanto é preciso recontar as histórias das civilizações humanas, a origem dos desenvolvimentos tecnológicos e quais as influências culturais presentes em nossa sociedade, acompanhado disso, problematizar as práticas de discriminação e preconceito presentes nas relações sociais, ou seja, tratar das diferenças e da diversidade humana, fortalecendo todo esse processo, formando nos educandos uma postura respeitosa e uma mudança de conceitos.

\section{UMA ABORDAGEM SOBRE O NEGRO NA EDUCAÇÃO}

Na história educacional dos negros a invisibilidade de sua inserção é um grande debate a ser explorado ainda que os mecanismos da escravidão tenham apartado o negro deste contexto, em seu processo de diáspora ele trouxe consigo saberes, práticas e ensinamentos que foram compartilhados e constituem os nossos costumes e práticas sociais, porém são poucas as informações sobre os períodos da colônia e império da inserção do negro na educação.

A educação para o negro representa um ato de resistência, já que o direito a Educação se constitui como uma negação histórica que com outros recortes ainda perdura. Compreendemos que nesse processo há uma marca histórica, um direcionamento condicionado ao lugar de ocupação de quem pesquisa e constrói essas narrativas, o que justifica a invisibilidade do negro nas contribuições expressas para construção da sociedade brasileira. Assim como a inserção do negro ao espaço escolar foi e tem sido um ato de resistência, a alteração da LDB (Lei de Diretrizes e Bases), se instituiu da mesma forma, obrigando o ensino de História e Cultura Africana e Afro-Brasileira, porém encontra cotidianamente dificuldades para sua aplicação, sobretudo no campo da formação de educadores.

Contudo, para contrapor a essas exclusões sociais a educação não escolar para o negro ocorria primeiramente nos espaços de resistência, como nos quilombos, nos terreiros, nas senzalas, em escolas alternativas, escolas noturnas, ou seja, mesmo na época da escravidão houve iniciativas educativas, e ainda que após a abolição da escravatura fosse dever do estado oferecer educação aos libertos, a educação pública foi negada de forma intencional, o estado por meios legislativos impediu o acesso a escolarização pública para os negros por meio de exigências e mecanismos de exclusão pautados num regimento de vestimentas, filiações responsáveis entre outros, para que mesmo em condição de liberdade, as crianças negras não pudessem acessar a educação fornecida pelo estado, como nos aponta as Diretrizes Curriculares Nacionais para a Educação das Relações Étnico-Raciais e para o Ensino de História e Cultura Afro-Brasileira e Africana:

O Brasil, Colônia, Império e República, teve historicamente, no aspecto legal, uma postura ativa e permissiva diante da discriminação e do racismo que atinge a 
população afro-descendente brasileira até hoje. O Decreto $\mathrm{n}^{\circ} 1.331$, de 17 de fevereiro de 1854, estabelecia que nas escolas públicas do país não seriam admitidos escravos, e a previsão de instrução para adultos negros dependia da disponibilidade de professores. O Decreto $\mathrm{n}^{\mathrm{o}}$ 7.031-A, de 6 de setembro de 1878, estabelecia que os negros só podiam estudar no período noturno e diversas estratégias foram montadas no sentido de impedir o acesso pleno dessa população aos bancos escolares.

Por isso uma das formas de fortalecer a inferiorização do negro foi negar o seu acesso ao ensino público, justificando a existência de uma incapacidade intelectual de aprendizagem, de construção e humanização o que trazendo para nossa atualidade se reflete nos discursos de alguns educadores quando atribui à dificuldade de aprendizagem, de parte dos alunos negros do ensino básico, a uma questão fisiológica, ou seja, percebe-se que esse discurso tem sua origem perversa e intencional desde o período escravocrata e mesmo com uma nova realidade de acesso educacional, enfrentamos as ideologias racistas do passado. A busca pela apropriação do saber escolar surge mesmo no estado de escravidão, porém o estado como responsável infelizmente atuou com um processo contrário, não vedando o acesso, mas impossibilitando-o sutilmente. Segundo Marileia Dos Santos Cruz (2005, p. 23);

Esse fato pode ser um dos aspectos que fazem pensar que alguns povos sejam mais sujeitos históricos que outros, dando a estranha impressão de haver povos sem história. A problemática da carência de abordagens históricas sobre as trajetórias educacionais dos negros no Brasil revela que não são os povos que não têm história, mas há os povos cujas fontes históricas, ao invés de serem conservadas, foram destruídas nos processos de dominação.

Foram criadas muitas políticas para afastar o negro dos centros escolares, comparando-se a uma política de cotas em que o branco que já ocupava um lugar de prestigio era o sujeito beneficiado. Para o negro, o saber escolar era uma forma de aproximação aos conceitos de civilização e afirmação social, por esse motivo a intencionalidade em dificultar o acesso. Atribuíase ao negro um atraso, heranças escravocratas não desejadas para uma sociedade moderna e civilizadas, mas a necessidade de exercer a cidadania após a libertação fez com que o negro se adequasse aos padrões e exigências oficiais já nos primeiros anos da república.

A educação vinculada à abolição da escravidão na verdade seria responsável por conservar os negros como trabalhadores subalternos, como base da pirâmide social: a educação foi reivindicada com propósitos claros de minimizar o processo de transformação da sociedade e conservar a ordem herdada do período escravocrata (FONSECA, 2002, p. 142). 
Ainda seguindo nesse viés encontramos nos tempos atuais uma resistência da classe dominante a política de cotas que é uma forma de negar, ou melhor, tentar conter o crescimento e ascensão social do negro nos espaços de poder, sendo um dos motivos que argumentam com um discurso ideológico de igualdade e democracia racial, pois temos direitos iguais, sendo assim não há necessidade para cotas. Por isso, a importância de serem trabalhadas as questões étnico/raciais nos espaços de educação, para que não haja somente um entendimento principalmente por parte dos sujeitos negros, mas abrangendo a toda população. Atender a uma demanda de cinco séculos de negação é um caminho árduo, mas não impossível é preciso mediar com o aluno negro a busca pelo saber e partindo primeiramente da sua história, contemplar a trajetória educacional dos povos afrobrasileiros é uma das diretrizes iniciais a serem seguidas.

\section{APLICAÇÕES DA LEI 10.639/03 E A CONSTRUÇÃO DA IDENTIDADE NEGRA}

A educação brasileira por muito tempo tem sido um veículo de reprodução do racismo e segregação social. O trabalho pela inclusão do negro na escola é uma resistência histórica em que a demanda da escolarização segue em processo. Sabemos que as condições socioeconômicas é um dos maiores entraves para a frequência e permanência dos alunos negros no espaço escolar, mas encontramos também uma grande lacuna nas práticas pedagógicas que não fortalecem o sentimento de pertencimento ao território da educação, muitos distanciamentos são causados pelas ausências e referenciais dentro do espaço. A escola precisa adotar políticas e estratégias pedagógicas que diante da demanda educacional estreitem as relações dos sujeitos com a escola, a qual precisa ser antes de um lugar de escolarização e aprendizagem, um espaço de pertencimento, de exercício de cidadania e construções identitárias. Segundo Petronilha (2003, p.3):

Reconhecimento implica justiça e iguais direitos sociais, civis, culturais e econômicos, bem como valorização da diversidade daquilo que distingue os negros dos outros grupos que compõem a população brasileira. E isto requer mudança nos discursos, raciocínios, lógicas, gestos, posturas, modo de tratar as pessoas negras. Requer também que se conheça a sua história e cultura apresentadas, explicadas, buscando-se especificamente desconstruir o mito da democracia racial na sociedade brasileira; mito este que difunde a crença de que, se os negros não atingem os mesmos patamares que os não negros, é por falta de competência ou de interesse, desconsiderando as desigualdades seculares que a estrutura social hierárquica cria com prejuízos para os negros. 
O olhar do educador para com os problemas e estigmas da sala de aula pode ser uma das possibilidades para que a desconstrução dos preconceitos aconteça. Partir do educador em elencar e discutir sobre as relações étnico-raciais com o intuito de valorizar os sujeitos negros e suas histórias, trabalhar com sensibilidade as diferenças e semelhanças, atuar na coletividade e também na individualidade. Para isso, o sistema de ensino precisa ter em seu quadro de professores, sujeitos competentes no trato das relações raciais, conhecedores dos conteúdos que abordem as questões históricas da população negra e branca, trabalhando de forma igualitária os conceitos e tensões para assim corrigir as problemáticas da discriminação racial. Muitas escolas reproduzem o discurso de que a escolarização é um mecanismo de promoção social, em especial para os alunos negros, porém sabemos que se não modificarmos as estratégias implantadas pelo sistema eurocêntrico, serão mantidas as práticas de dominação oriundas do escravismo. Nesse sentido Petronilha (2004, p. 06) afirma que:

Para obter êxito, a escola e seus professores não podem improvisar. Têm que desfazer mentalidade racista e discriminadora secular, superando o etnocentrismo europeu, reestruturando relações étnico-raciais e sociais, desalienando processos pedagógicos. Isto não pode ficar reduzido a palavras e a raciocínios desvinculados da experiência de ser inferiorizados vividas pelos negros, tampouco das baixas classificações que lhe são atribuídas nas escalas de desigualdades sociais, econômicas, educativas e políticas.

Uma das atribuições do educador é estabelecer o sentimento de pertencimento positivo dos alunos a um grupo social de prestigio, para isso sua postura política precisa estar atrelada a esse conceito, o olhar dos sujeitos educadores é reflexo de suas convicções políticas, sociais e raciais, sendo preciso desconstruir preconceitos para então construir conceitos que irão respaldar suas práticas pedagógicas. Estão presentes ainda nas práticas docentes vícios e valores de uma sociedade escravistas que direcionam os alunos, em destaque os negros, a um lugar de subalternidade. Os preconceitos sociais que atribuem as habilidades de mão-de-obra como inata dos afrodescendentes não estão presentes apenas nos espaços escolares, esses conceitos estereotipados estão para além dos muros da escola, mas é dentro desses muros que temos a oportunidade de combatê-los.

Infelizmente muitos educadores não demonstram interesse em dominar os conteúdos de história e cultura africana, o que dificulta a aplicação da lei 10.639/03, por esse caminho consideramos esse um dos maiores entraves para que o espaço escolar se constitua como um espaço de pertencimento para todos os sujeitos e não somente para os não negros, como se intencionou nos períodos iniciais da república. Sendo assim, construir estratégias educacionais que combatam o 
racismo é uma responsabilidade predominantemente dos educadores. Recorro ao parecer de Petronilha (2004, p.9) para confirmar que:

Precisa, o Brasil, país multi-étnico e pluricultural, de organizações escolares em que todos se vejam incluídos, em que lhes seja garantido o direito de aprender e de ampliar conhecimentos, sem ser obrigados a negar a si mesmos, ao grupo étnico/racial a que pertencem e a adotar costumes, ideias e comportamentos que lhes são adversos.

Os educandos são sujeitos que exprimem em seus comportamentos traços históricos renegados pela sociedade, sua corporeidade marcada pela afrodescendência encontra no cotidiano escolar conflitos de representações, em maioria relações negativadas pelo racismo e estereótipos, por isso o olhar do educador precisa atingir os materiais didáticos, pois sabemos que existem exigências do sistema para utilização desses conteúdos e como não é possível retirá-los dos regimentos de uso, a utilização precisa ser criticamente aplicada, usá-los de forma reflexiva como referenciais para a ressignificação das práticas sociais, para modificar as relações étnico-raciais, ou seja, articular sujeitos- conteúdos - sujeitos, promovendo uma compreensão de para quem serve a educação brasileira e seus conteúdos, é levar os educandos a produzirem um pensamento crítico sobre seu lugar, sua constituição de sujeito social, sendo sujeito de direitos que precisam ter suas raízes africanas valorizadas e reconhecidas assim como as raízes europeias que estão impostas nos currículos escolares, não se trata de impor um currículo de matriz africana, mas um currículo para a diversidade, que contemple antes das semelhanças, as diferenças.

Incluir o negro na escola é uma luta histórica, incluí-lo positivamente nos registros históricos é uma constante que requer a abordagem das contribuições africanas em todas as áreas de conhecimento, partindo de uma educação transversal, pois como nos diz Nilma Lino Gomes (2003, p.5):

Essas concepções e essas práticas pedagógicas, repletas de valores e representações negativas sobre o negro, resultam, muitas vezes, na introjeção do fracasso e na exteriorização do mesmo pelos alunos e alunas, expresso numa relação de animosidade com a escola e com o corpo docente. Diante de uma estrutura e de práticas excludentes não é de se estranhar que muitos/as alunos/as negros/as introjetem o racismo e o preconceito racial.

O educador precisa ressaltar as contribuições dos negros, por exemplo, na produção inicial, no domínio e uso das tecnologias da humanidade. Precisamos sair dos discursos de um currículo generalista que ignora as partes do todo que é a humanidade, onde sendo a África o berço da humanidade, é negada a sua origem como pertencente, tratam-se as raízes africanas como 
intrusas na construção da civilização brasileira, contrapor essa ideologia é um dos principais objetivos da lei 10.639/03, pois é preciso resgatar a memória, resgatar a ancestralidade, construir uma memória positiva, afinal foram os grandes impérios africanos que contribuíram para o desenvolvimento da humanidade. Em concordância com Nilma Lino Gomes (2003, p.8):

Ao levarmos a sério essa questão e buscarmos construir estratégias de reversão do quadro de desigualdade social e racial, estaremos nos posicionando politicamente, e isso implica discordâncias, negociações, acordos e tensões.

É no ensino de história e cultura africana que poderemos modificar as práticas pedagógicas, o olhar para o sujeito negro e sua história, ressignificando a educação normativa, que reforçam os discursos colonialistas de controle e opressão. As práticas pedagógicas precisam ser construídas a partir da realidade social dos sujeitos do espaço escolar. Reverter o processo de discriminação racial é reeducar o olhar pedagógico para a população negra e suas necessidades, pois a representatividade e o reconhecimento histórico foram e são ao longo da história um problema social, sendo assim partiremos então pelos pontos de resistência, é preciso considerar a diversidade como constituinte da história brasileira.

\section{O SILENCIAMENTO E O RECONHECIMENTO DA ALTERIDADE NEGRA}

A questão da alteridade negra quando considerada dentro do espaço escolar nos remete a muitas reflexões, afinal olhar para o outro e considera-se como diferente dentro de um espaço em que ser diferente tem sido anormal ou inferior é um processo conflituoso. A educação dita para todos um discurso de camuflagem para a falsa ideologia de democracia racial e sociedade igualitária, pois não se pode tratar com neutralidade as diferenças evidentes.

A alteridade negra esta constituída por diversos fatores rejeitados pela sociedade sendo os principais pautados nos traços físicos e na religião, considerando esses dois pontos que dentro do espaço escolar são referenciais nos apelidos, como exemplo (macumbeiro, boneca de macumba, feiticeiro, cabelo ruim, macaco, carvão mineral, picolé de betume entre outros), por esse motivo pode ser um caminho complexo dentro da trajetória escolar de um educando e sua alteridade, construírem uma identidade positiva, como nos afirma Elisa Larkin Nascimento (2003, p. 30):

A identidade pode ser vista como uma espécie de encruzilhada existencial entre indivíduo e sociedade em que ambos, vão se constituindo mutuamente. Nesse processo o indivíduo articula o conjunto de referenciais que orientam sua forma de agir e de mediar seu relacionamento com os outros, com o mundo e consigo mesmo. 
Desse modo, trazer para o contexto escolar os debates em torno das diferenças e diversidade como necessidade e constituição da humanidade que inclui ou exclui um sujeito, poderá minimizar os conflitos, desconstruindo os preconceitos incutidos nos saberes eurocêntricos da sociedade brasileira, pois sabemos que a educação é organizada pelos valores e crenças que a sociedade produziu ao longo de sua construção social e cultural. Ainda que a escola omita o preconceito existente e alimentado na consciência dos alunos pelas representações apresentadas no cotidiano escolar, não será possível transferir a responsabilidade pelo fracasso de seus alunos negros como um reflexo de sua condição socioeconômica, pois no que envolve as relações de aprendizagem é no distanciamento cultural e afetivo que as ideologias da classe dominante se estabelecem, afetando a imagem criada pelo aluno de si mesmo e sua autoestima. Como relata Vanda Machado (2013, p.34):

Ao longo da minha caminhada pela vida aprendi, constatei e, principalmente, senti que as crianças negras carecem de um olhar diferenciado. Um olhar que contemple sua beleza do jeito como ela é. As crianças negras crescem tomando tapas na alma. Não fomos rainha do milho. Não fomos rainha da primavera. Votávamos em rainhas que não nos representavam: rainha do milho, rainha da primavera, rainha do grêmio. A eleita era sempre uma menina que não tinha nenhuma obrigação de se incomodar com a nossa agonia. Era uma situação naturalizada. Também nunca percebi que eu não podia ser anjinho porque meu cabelo não balançava.

Muitos professores ignoram a alteridade de seus alunos, estigmatizando sua identidade e seu direito a diferença, infelizmente a educação brasileira ainda vivencia um silenciamento pedagógico em seu cotidiano, alimentando a ilusão de uma sociedade igualitária, camuflando as evidencias em que os privilegiados e os marginalizados continuam ocupando os mesmos espaços. Porém, o que antes era imposto por meios legais, no caso o impedimento das crianças negras no período pós-abolicionista a escolarização, hoje tem sido combatido também por meios legais através da promulgação da lei 10.639/03. Por meio das ações afirmativas é que muitos educadores abordam as questões raciais e contribuem para reparação das desigualdades sociais e raciais presentes na educação brasileira. Nesse sentido, segundo Paulo Freire (1978, p.16):

Por tudo isto é que, para os colonizados que passaram pela alienante experiência da educação colonial, a "positividade" desta educação ou de alguns de seus aspectos só existe quando, independentizando-se, a rejeitam e a superam. Quando, assumindo com seu povo, a sua história, se inserem no processo de "descolonização das mentes", a que faz referência Aristides Pereira; processo que se alonga no que Amílcar Cabral chamava de "reafricanização das mentalidades." 
Trazendo esse pensamento para os dias atuais é necessário compreender que a sociedade precisa se reeducar, os professores precisam "reafricanizar" suas práticas pedagógicas, onde as relações entre negros e brancos precisam ser ressignificadas através de trocas, de aprendizagens coletivas, onde a consciência negra precisa ser trabalhada em todos os sujeitos envolvidos na educação, ao desalienar os currículos e o fazer pedagógico. Portanto, dialogar com as diferenças implica em reconhecer e trabalhar a alteridade na educação não ensinar o educando para o ato de tolerância, mas é construir no outro o sentimento de respeito e construção possível de novos conhecimentos, de novas possibilidades, pois aprender novos modos, novos conceitos é uma forma de ampliar-se enquanto sujeito histórico e vivo.

Refletir sobre as práticas pedagógicas silenciadas é um deslocamento enquanto sujeito educando e educador, onde ao resgatarmos em nossa memória de educando vivencias do cotidiano escolar em que os conflitos raciais e sociais se estabeleceram, raramente serão relatadas intervenções críticas, libertadoras e emancipatórias pelo corpo docente ou escolar, acredito que ao menos para os sujeitos não negros vivenciar situações de racismo ou discriminações em sua trajetória escolar, foi e é uma processo naturalizado. Partindo desse contexto e como ressalta Jurjo Torres Santomé (1995, p.169):

E frequente que tanto as autoridades políticas, quantos os professores e professoras se vejam a sim mesmo/as como pessoas objetivas, neutras e, por conseguinte, como pessoas que não favorecem a reprodução e produção de comportamentos racistas. Entretanto quando se fazem analises etnográficas no interior das salas de aula ou se observam os materiais curriculares, logo aparecem diante, de nossos olhos, condutas que invalidam as auto-imagens de neutralidade que o sistema educacional oferece.

Para isso, partir da desconstrução do universalismo presente no currículo e consequentemente na pratica pedagógica é uma das formas de romper com o silenciamento pedagógico que tanto afeta a construção de identidade positiva dos educandos. É necessário refletir sobre o ato de educar, pois ausência do trato com a alteridade do educando é uma marca que se naturaliza no contexto escolar, e sendo a escola um espaço ideológico de poder, utilizar-se criticamente dessa influência na formação de um sujeito social é determinante no seu processo de construção de identidade. Por esse motivo, deslocar-se enquanto sujeito social é uma necessidade para o educador, sendo a sua formação um dos caminhos emancipatórios para pratica de uma pedagogia antirracista e uma educação libertadora. Em acordo a essa necessidade me apoio no que diz Luiz Alberto Oliveira Goncalves (1985, p. 171): 
Em meio a tantas revoltas, as classes dominantes criaram mecanismos de força e de violência tanto física quanto simbólica para sufocar o rebelde. Educar-se negro é educar-se rebelde, e, por isso, não foi por acaso que a escola, entre outras coisas, tenta esconder a história da rebeldia do negro.

Portanto reconhecer a alteridade dos sujeitos inseridos na escola trilhando caminhos emancipatórios na educação é uma necessidade que emerge dos conflitos sociais. Implica nesse sentido formar um educando negro e não negro para a democracia diante de uma sociedade que não reconhece a desigualdade social, não assume a discriminação racial, marginaliza culturas, demoniza religiões e estereotipa etnias. Destacamos como problemáticas que atinge em sua predominância os negros, por esse motivo os fatos históricos em que o negro protagoniza lutas, movimentos sociais, bem como conhecimentos científicos que foram determinantes ao desenvolvimento da humanidade precisam ser revelados, apresentados e potencializados como dispositivos de insurgências contra o silenciamento na aprendizagem, para que assim o fazer pedagógico fortaleça a tomada de consciência e a representatividade reflita na atuação social dos sujeitos. 


\section{REFERÊNCIAS}

CRUZ, Marileia dos Santos. Uma abordagem sobre a história da educação dos negros IN: ROMAO, Jeruse (Org.) História da Educação do Negro e outras histórias. Brasília, Ministério da Educação, Secretaria de Educação Continuada, Alfabetização e Diversidade. 2005

FONSECA, Marcus Vinícius. A educação dos negros: uma nova face do processo de abolição da escravidão no Brasil. Bragança Paulista: EDUSF; 2002.

FREIRE, Paulo. Pedagogia da autonomia: saberes necessários a prática educativa. São Paulo: Paz e Terra, 1978.

GOMES, Nilma Lino. Educação, identidade negra e formação de professores/as: um olhar sobre o corpo negro e o cabelo crespo. Educação e pesquisa, São Paulo, v29, n1, p.167-182, jan. /Jun, 2003. Disponível em: < http://www.scielo.br/pdf/ep/v29n1/a12v29n1.pdf > Acesso em: 20 dez 2016.

GOMES, Nilma Lino. Educação e identidade negra. Aletria: alteridades em questão. Belo Horizonte, MG, v. 06, n.09, dez/2002, p. 38-47. Disponível em: < http://ideario.org.br/wp/wp-content/uploads/2013/10/nilma-lino.pdf > Acesso em: 20 jan 2016.

GOMES, Nilma Lino. Alguns termos e conceitos presentes no debate sobre relações raciais no Brasil: Uma breve discussão. Educação anti-racista: caminhos abertos pela Lei Federal n ${ }^{\circ}$ 10.639/03 / Secretaria de Educação Continuada, Alfabetização e Diversidade. - Brasília: Ministério da Educação, Secretaria de Educação Continuada, Alfabetização e Diversidade, 2005.

GONÇALVES, Luis Alberto Oliveira. O silêncio: um ritual pedagógico a favor da discriminação racial: (um estudo acerca da discriminação racial como fator de seletividade na escola pública de primeiro grau - $1^{\text {a a }} 4^{\text {a }}$ série). UFMG, 19/12/1985.

LUZ, Narcimária Correia do Patrocínio. É preciso africanizar a universidade. In: MENEZES, J. M. F.; SANTANA, E. C. ; AQUINO, M. S. . Educação, região e territórios - formas de inclusão e exclusão. 1. ed. Salvador: Edufba, 2013. v. 1. P. 173-199.

MACHADO, Vanda. Pele da cor da noite. Salvador: EDUFBA, 2013.

MENDES, Bartolomeu de Jesus. Entre blocos afros e afoxés, Liberdade - Salvador/BA. no último quartel do Séc. XX (Identidade e Diferença na intersubjetividade). Programa de Estudos Pós-graduados em História Social da PUC/SP (Doutorado). São Paulo/SP, 2008: 305 fs.

MUNANGA, Kabengele. Negritude: usos e sentidos. São Paulo: Ática, 1986.

MUNANGA, Kabengele. Rediscutindo a mestiçagem no Brasil: identidade nacional versus identidade negra. 2 ed. Belo Horizonte: Autentica, 2006.

MUNANGA, Kabengele (org.). Superando o racismo na escola. 2 ed. Brasília: Ministério da Educação, Secretaria de Educação Continuada, Alfabetização e Diversidade, 2005.

MUNANGA, Kabengele. Uma Abordagem Conceitual das Noções de Raça, Racismo, Identidade e Etnia IN: BRANDÃO, André Augusto P. Programa de Educação Sobre o Negro na Sociedade Brasileira, Ed. EDUFF, Rio de Janeiro, 2004.

NASCIMENTO, Elisa Larkin. Sankofa: Educação e Identidade Afrodescendente. IN: CAVALLEIRO, Eliane (org.). Racismo e antiracismo da escola: repensando nossa escola. São Paulo: Selo Negro, 2001.

NASCIMENTO, Elisa Larkin O sortilégio de cor: identidade, raça e gênero no Brasil. São Paulo: Selo Negro, 2003.

SANTOMÉ, J. T. As culturas negadas e silenciadas no currículo. In: SILVA, Tomaz Tadeu (Org.). Alienígenas na sala de aula. Petrópolis, RJ: Vozes, 1995.

SANTOS, Boaventura de Sousa. Para uma sociologia das ausências e uma sociologia das emergências. Revista Crítica de Ciências Sociais, 63, outubro/2002. Disponível em: < https://rccs.revues.org/1285 > Acesso em: 20 dez 2016.

SILVA, Petronilha Beatriz. Aprendizagem e Ensino das Africanidades Brasileiras. IN: MUNANGA, Kabengele (org.). Superando o racismo na escola. 2 ed. Brasília: Ministério da Educação, Secretaria de Educação Continuada, Alfabetização e Diversidade, 2005.

SILVA, Petronilha (Relatora). Diretrizes Curriculares Nacionais para a Educação das Relações Étnico-Raciais. Brasília - DF: Conselho Nacional de Educação, 2004.

ROMÃO, Jeruse. O Educador, A educação e a Construção de Uma Auto Estima Positiva do Educando Negro IN: CAVALLEIRO, Eliane (org.). Racismo e anti-racismo da escola: repensando nossa escola. São Paulo: Selo Negro, 2001. 


\section{RESUMO}

Este artigo discute as relações entre educação, fazer pedagógico e a construção de identidade negra dentro do espaço escolar. Articular conceitos e vivencias desta pesquisa é importante para refletir sobre as práticas pedagógicas e como elas podem afetar o educando em sua particularidade, autoestima e aprendizagem. Contudo, através da escola que classes dominantes bem como os poderes políticos e sociais direcionam o currículo e as práticas pedagógicas desse contexto para oprimir e negligenciar epistemologias que não atendem ao viés hegemônico. Sendo assim, dividimos a produção textual em três momentos interdependentes. Em primeiro, explanamos uma perspectiva história do negro na Educação Brasileira. Em seguida, reportamos a Lei 10.639/03 na construção da identidade dos educandos. Já o terceiro momento, abarcamos a naturalização do silenciamento perante discussões étnico raciais.

Palavras-chave: Educação. Identidade negra. Silenciamento pedagógico.

\section{BLACK IDENTITY, EDUCATION AND SILENCING: THE PEDAGOGICAL LOOK FOR THE APPLICATION OF LAW 10.639 / 03}

\section{ABSTRACT}

This article discusses the relationships between education, pedagogical doing and the construction of black identity within the school space. Articulate concepts and experiences of this research is important to reflect on pedagogical practices and how they can affect the learner in their particularity, self-esteem and learning. However, through the school, ruling classes as well as political and social powers direct the curriculum and pedagogical practices of this context to oppress and neglect epistemologies that do not meet the hegemonic bias. Thus, we divide textual production into three interdependent moments. First, we explain a black history perspective in Brazilian Education. Next, we report Law 10.639 / 03 on the construction of the identity of students. In the third moment, we cover the naturalization of the silencing before racial ethnic discussions.

Keywords: Education. Black identity. Pedagogical silencing.

\section{IDENTIDAD NEGRA, EDUCACIÓN Y SILENCIO: LA MIRADA PEDAGÓGICA PARA LA APLICACIÓN DE LA LEY 10.639 / 03}

\section{RESUMEN}

Este artículo discute las relaciones entre educación, hacer pedagógico y la construcción de identidad negra dentro del espacio escolar. Articular conceptos y vivencias de esta investigación es importante para reflexionar sobre las prácticas pedagógicas y cómo pueden afectar al educando en su particularidad, autoestima y aprendizaje. Sin embargo, a través de la escuela que clases dominantes así como los poderes políticos y sociales dirigen el currículo y las prácticas pedagógicas de ese contexto para oprimir y descuidar epistemologías que no atienden al sesgo hegemónico. Siendo así, dividimos la producción textual en tres momentos interdependientes. En primer lugar, explicamos una perspectiva histórica del negro en la Educación Brasileña. A continuación, reportamos la Ley 10.639 / 03 en la construcción de la identidad de los educandos. En el tercer momento, abarcamos la naturalización del silenciamiento ante discusiones étnicas raciales.

Palabras-clave: Educación. Identidad negra. Silenciamiento pedagógico. 